Please cite this publication as follows:

Boon, W. P., Chappin, M. M., \& Perenboom, J. (2014). Balancing divergence and convergence in transdisciplinary research teams. Environmental Science \& Policy, 40, 57-68. 


\section{Balancing divergence and convergence in transdisciplinary research teams}

Wouter P.C. Boon ${ }^{\mathrm{a} \mathrm{b}^{*}}$, Maryse M.H. Chappin ${ }^{\mathrm{a}}$, Jaap Perenboom ${ }^{\mathrm{c}}$

a Innovation Studies, Copernicus Institute of Sustainable Development, Utrecht University, Heidelberglaan 2, 3584 CS Utrecht, the Netherlands.

b Rathenau Instituut, Anna van Saksenlaan 51, PO Box 95366, 2509 CJ Den Haag, The Netherlands.

${ }^{\mathrm{c}}$ No current affiliation.

* Corresponding author:

Wouter P.C. Boon

Innovation Studies, Copernicus Institute of Sustainable Development, Utrecht University, Heidelberglaan 2, 3584 CS Utrecht, the Netherlands. Phone: +31(0)302532708.

w.p.c.boon@uu.nl 


\section{Vitae}

Wouter Boon is assistant professor in Innovation Studies at Utrecht University.

Maryse Chappin is assistant professor in Innovation Studies at Utrecht University.

Jaap Perenboom conducted his Master thesis in the field of organisation studies at Tilburg University.

\section{Acknowledgements}

The research project Comparative Monitoring of Knowledge for Climate (project SSA01) is carried out in the framework of the Dutch National Research Programme Knowledge for Climate (www.knowledgeforclimate.org). This research programme is co-financed by the Ministry of Infrastructure and the Environment. We would like to thank the interview respondents for providing us with information, as well as Dries Hegger, Edwin Horlings and Tjerk Wardenaar for their valuable comments. 


\title{
Balancing divergence and convergence in transdisciplinary research teams
}

\begin{abstract}
Climate adaptation projects often involve joint knowledge production, including different stakeholders and disciplines. One of the main challenges of transdisciplinary research projects is to balance the convergence and divergence of epistemic contributions. We explore to what extent organisational embedding of project teams, input in the project, and project governance influence project performance in climate adaptation projects. Our results indicate that aligning incentive systems and lower partner diversity lead to higher effectiveness and satisfaction. Project size enhances effectiveness, but decreases satisfaction. Satisfaction is enhanced by committed project members. Furthermore, dealing with diverse partner sets and large teams is not eased by careful management in the course of the project. Careful balancing of divergence and convergence should be taken into account during the design stage of these projects. In the context of knowledge co-production for environmental challenges, project management should proactively consider project structure, required level of partner diversity and project size.
\end{abstract}

\section{Keywords:}

Joint knowledge production; co-production; transdisciplinarity; project governance; climate adaptation 


\section{Introduction}

For over a decade research on how to adapt to the consequences of climate change has steadily been gaining momentum (Biesbroek et al, 2010; Ford et al, 2011). Finding solutions to these kinds of complex or 'wicked' problems requires transdisciplinary or joint knowledge production, taking into account experiential and localised knowledge, integrating different disciplines, and involving a wide range of actors in the research process itself (Nowotny et al., 2001; Pohl, 2008). Including traditional knowledge users, like policymakers and companies, contributes to producing legitimised and effective knowledge and to reconciling supply and demand for knowledge (Sarewitz and Pielke, 2007; McNie, 2007; Boon et al., 2011).

Climate adaptation projects are often positioned at the cross-section of science, policy and practice, which signals the need for including different stakeholders and disciplines in the production of knowledge. Examples of such projects are research on flooding in unembanked areas and health impacts of urban heat. In these projects academic researchers collaborate with people working at non-academic institutes, municipalities, district water boards, companies, etc. In various research systems, knowledge co-production projects concerning climate adaptation have become more prominent. These projects were often shaped in the context of large-scale, multi-actor research programmes. Examples include Knowledge for Climate (the Netherlands), KLIMZUG (Germany), and NOAA RISA (US). Despite this increase in prominence, questions remain about success and the management of these kinds of programmes, calling for research on the performance and governance of these kinds of projects. To study this, we looked at climate adaptation projects in the Dutch Knowledge for Climate programme.

Organising knowledge co-production is not straightforward. The management of transdisciplinary research is complex and non-linear due to differences in knowledge backgrounds, normative perspectives, time frames and reward structures (Edelenbos et al., 2011; Hegger et al., 2012a). Although transdisciplinary research projects need to nurture divergence, the project format dictates the intention to generate convergent end products. This article focuses on this balancing act of convergence and divergence of epistemic contributions. The central question is how project and contextual aspects influence team performance in transdisciplinary climate adaptation projects.

To explore this research question and learn more about this balancing act in relation to project governance we use insights from organisation and science studies. Ample research has been done on collaborations in science (cf. Parker et al., 2010) and in the context of projects inside organisations (Hobday, 2000). Studies on networks focus more on intra- 
organisational networks than on networks between organisations (Ibert, 2004; Provan, et al., 2007). Most inter-organisational studies, though, focus on whole-network level (Provan et al., 2007), interuniversity collaborations (Chompalov et al., 2002) or on temporary organisations working on specific tasks (cf. Bakker, 2010), such as ship-building projects (Levering et al., 2013). Most of the studies do not focus on scientific projects pertaining to a diverse range of actors, disciplines and locations. Our paper adds to the current literature by studying interorganisational, transdisciplinary projects that aim to govern knowledge diversity in climate adaptation projects. Another contribution of this paper lies in the fact that transdisciplinary projects have been studied conceptually, whereas empirical investigations are rare (Pohl, 2010; Hegger et al, 2012b).

To address these issues, we introduce the aspects we focus on first while drafting the theoretical framework (section 2). The methodological set-up of the article is explained in section 3, followed by the results (section 4) and the discussion and conclusions (section 5).

\section{Theoretical framework}

\subsection{Performance of inter-organisational and transdisciplinary projects}

This paper focuses on temporary transdisciplinary, inter-organisational teams consisting of knowledge users and producers coming from different organisations, disciplines and normative backgrounds. These teams work on a project in which the development of new knowledge transcends the boundaries of traditional knowledge producers and users. These transdisciplinary research projects are positioned between different organisations. The setup of such a project offers several advantages. First, temporal collaboration between actors with heterogeneous cognitive and normative backgrounds creates room for out-of-the-box learning (March, 1991). Second, from innovation management we know that innovative projects need to be set up separate from the business-as-usual operations. This enhances flexibility and creates a nursery that is not (yet) subject to the hard performance criteria (Jones and Lichtenstein, 2007).

At the same time, compartmentalising activities in an inter-organisational project might lead to challenges, such as alignment of project activities with activities in the participating organisations and communication between project members and their own organisations (Bercovitz and Feldman, 2011). These coordination costs are augmented through the need to combine different epistemic backgrounds. 
Using concepts from organisation and science studies, we want to explore the performance of these transdisciplinary projects. Multiple dimensions are proposed to conceptualise project performance. First, De Wit (1988) and Cooke-Davies (2002) perceive effectiveness, i.e. the extent to which its objectives are attained, as the most appropriate criterion for project performance. Kenis and Provan (2009) also used effectiveness to measure project performance in inter-organisational networks. The above indicates the relevance of this dimension, which supports the application of this dimension in the context of transdisciplinary projects.

Second, satisfaction of project members has been regarded as a significant complementary dimension (Kenis and Provan, 2009; Provan and Milward 2001). Whereas effectiveness signifies goal attainment, satisfaction adds the evaluation of the experience of the process that project participants went through. The differences in organisational backgrounds and the absence of predefined routines to cooperate make these processes potentially complex and cumbersome. By this, satisfaction complements effectiveness, which focuses on direct project outcomes, as a dimension for project performance.

\subsection{Factors influencing performance of transdisciplinary teams}

Transdisciplinary teams need to nurture heterogeneity and diversity in terms of knowledge, organisations, etc. but at the same time create an univocal product. This can be regarded as part of a balancing act between diversity (divergence) and alignment (convergence). For example, stakeholders and disciplines that participate are diverse but during the project their endeavours need to converge to an end product. In studying the driving forces behind project performance, we want to include variables that cover this balancing act.

In organisational sciences ample research is conducted about the way in which teams are arranged effectively. A wide range of factors is discerned that influence team effectiveness. Stokols et al. (2008) propose contextual factors, such as physical/environmental (spatial proximity), technological (data infrastructure) and sociopolitical ones. Institutional factors play a prominent role, e.g. in the form of incentive systems, as well as personal ones, e.g. regarding motivations (Brown and Eisenhardt, 1995; Cohen and Bailey, 1997). Team structure, team climate, team processes, and leadership style are also often regarded as contributing to team functioning (Anderson et al., 2004; Verbree, 2011).

Even though the studies mostly focus on intra-organisational teams, these identified factors are also expected to be relevant for inter-organisational teams. Team characteristics concerning structure, climate and processes apply to inter-organisational projects as well, and 
are crucial in structuring interactions between team members coming from distinct organisations and answering to different objectives. In organisational sciences literature the factors influencing project performance can be subdivided into three categories: 1) input to project with the aim to generate output, 2) the project's environment, and 3) project management. Following this structure, we focus on the following forces that drive the balance between divergence and convergence: the embeddedness of the project team in the organisational contexts, the input in the project, and project governance. These driving forces are discussed below.

1) Embeddedness of the project team: alignment of project team and participating organisations

The embedding of inter-organisational projects in their environment can be precarious. Results might be absorbed quite readily in project teams, but the singular organisational setting and the highly-contextualised nature of the knowledge produced makes transferability of knowledge more complicated (Hobday, 2000; Ibert, 2004). These transferability issues have repercussions for the organisation of teams. Teams might have a single principal but team members experience pressure of at least one other source, such as the prevailing norms in their 'home organisation'. In this context, alignment concerns the difference between the rewards for project participation and the assessment by their home organisation, and whether there are any tensions between the project work and the work they need to do for their own organisation (Ibert, 2004; Cummings and Kiesler, 2007; Bercovitz and Feldman, 2008). If the incentives of projects participants are aligned to those in the home organisations, e.g. by applying special rewards for project work, then project members are protected from direct pressures from their home organisation and are rewarded for their work in the project team. Alignment will result in higher levels of goal obtainment and in more satisfied project members.

\section{2) Input in the project: partner diversity, partner commitment, and project size}

Transdisciplinary projects host a diverse set of participators' cognitive and normative backgrounds. On the one hand partner diversity is beneficial for the effectiveness of these projects, because contributions from distinct disciplines and practical contexts create knowledge combinations that are innovative and applicable in different contexts (Bercovitz and Feldman, 2011). A wider range of expertise areas and potential solutions can be used in the creative process of teams (Dahlin et al., 2005). Combining does not necessarily mean 
reaching consensus or full integration because that does not necessarily lead to workable solutions (Roelofsen, et al., 2011). Challenging each other's input might be just as useful. The same reasoning applies to the normative backgrounds of participating actors. This is positive for the effectiveness of the knowledge co-production projects.

On the other hand, the degree of diversity should not be too high; otherwise project partners are unable to understand each other's ideas (Nooteboom, 1999). Knowledge transfer requires sufficient absorptive capacity, i.e. resources that enable an actor to assimilate novel knowledge (Cohen and Levinthal, 1990). Therefore, scholars argue that there is an optimal cognitive distance with respect to learning possibilities (Nooteboom, 1999). This takes the form of an inverted U-shape relationship in the sense that both low and high scores on partner diversity are associated with low levels of learning potential and innovativeness and moderate scores on partner diversity are associated with high levels (Wuyts et al., 2005; Gilsing et al., 2008). If we transfer these results to our context of knowledge co-production, such an optimum of diversity levels can also be expected related to project effectiveness.

However, for the relation between project diversity and satisfaction we expect something different. The main mechanism for this relation is that too much diversity lowers the ability to understand each other (Nooteboom, 1999). Larger differences between the project partners increase misunderstanding. This might result in less satisfied project members.

Another aspect of project input is the commitment of project members. Commitment can take many forms, such as the additional effort put into project work, efforts put into transferring project results to the home organisations and other interested parties, and openness to other actors' values, norms and goals. Team literature shows that efforts of project members and openness towards each other positively influence project performance (e.g. Hackman, 1987; Hoegl and Gemeunden, 2001; Sarewitz, 2004). Motivation of project members is important for project performance (De Wit 1988). The literature on inter-organisational relations also reveals that strong ties might be beneficial for innovation (Uzzi, 1997). Strong ties reflect commitment that results in exchanging fine-grained information (Zaheer et al., 1998) and more intense collaboration. In short, higher levels of commitment are expected to raise project performance, because they will make it easier to achieve project goals and to collaborate. 
A final dimension of project input is project size. There is ample but ambiguous literature on the effect of team size on effectiveness (Stokols et al. 2008). On the one hand, larger projects tend to offer more opportunities and widening access to resources. These resources can positively influence the performance of the projects (Baum et al., 2000). Since more organisations are involved in such a larger project, more knowledge will be available that can be used for co-producing knowledge. This will enable projects to obtain their goals and will result in higher levels of effectiveness. On the other hand, project size can negatively influence project performance. Team research shows that large projects experience more difficulties with respect to group processes (Levine and Moreland, 1990). First, in larger projects project members are less visible to other project members. This anonymity might induce opportunistic behaviour. Second, in larger projects it is much more difficult to inform each other, which results in unawareness of the progress of other partners.

\section{3) Project governance: project structure and project management}

A focal point for governing transdisciplinary teams is the management of heterogeneity, in terms of cognitive contributions, norms, values and so on. By definition, these projects aim to combine and integrate knowledge reservoirs coming from distinct actors. As the discussion of the embedding of the project team and partner diversity above shows, dealing with heterogeneity is a balancing act. Diverging and converging forces need to be aligned, which calls for careful and active project governance. Our study focused on two dimensions of project governance: project structure and project management.

First, project structure is discussed in the context of task division, which concerns the way research tasks are distributed among team members. This has a cognitive element, i.e. the extent to which the content is integrated, but it also reflects on the organisation of the team’s work. Hara et al. (2003) discern ‘complementary’ versus ‘integrative’ collaboration. Complementary collaboration means working together on a project but doing this sequentially or in parallel, without real interaction and cross-pollination. Knowledge coproduction occurs at the end of the project, when these compartments are taken together and integrated, usually by one actor. Such a set-up is structured in the form of a centralised network. Integrative collaboration concerns doing research in close collaboration with participants; together developing research problems, plans, data gathering, analysis and reporting. This is organised through a decentralised network structure. Team literature shows that a decentralised structure facilitates collaboration (Sparrowe et al., 2001). Also for decision making in teams it has been shown that such a collaborative structure is beneficial 
(Curseu et al., 2013). A decentralised structure might reduce the negative effects resulting from diversity, because problems related to misunderstanding each other might be reduced.

Second, we have studied the project management. Proper project management contributes to project performance (De Wit, 1998) and the temporal and inter-organisational character of projects, implying that there are no routines, makes active project management even more significant. The way projects are organised right from the start is regarded as crucial for team performance (Ericksen and Dyer, 2004). Project management might enable project members from different backgrounds to benefit from their different knowledge bases and prevent problems in understanding each other.

\section{Methodology}

\subsection{Context and case selection}

In this paper we conducted a comparative case study of 15 inter-organisational transdisciplinary research projects. In addition, two of these projects were also studied indepth to serve as illustrative cases. All investigated projects are part of "Knowledge for Climate”, a large-scale research programme that studies adaptation to climate change. Programme initiators envisaged that reacting on future consequences of climate change means focusing on regional and local adaptation measures (Kabat et al, 2005). The programme was arranged accordingly, delegating a major part of research to nine so-called 'hotspots'. The governing bodies of these hotspots consist of stakeholders such as municipalities, water boards, regional authorities and companies. Some of these hotspots are indeed more locally concentrated, such as the Rotterdam region and port, and Amsterdam Airport Schiphol. Others are formulated thematically, such as the hotspots focussing on 'dry rural areas' and 'shallow waters and peat meadow areas'. The idea behind these hotspots is that knowledge is developed as part of a co-production process of universities, non-academic research institutes and societal partners.

Research is conducted in three so-called tranches which should ultimately form input for drafting regional adaptation strategies. The first tranche consisted of projects addressing urgent knowledge questions. This was followed by a second tranche of more scientificallyinclined projects and a third tranche in which adaptation strategies were devised. We focus in our study on the first tranche, since most projects in this phase are completed, making it 
possible to take outcomes into account and projects in the others tranches were still running at the time of the period of data collection.

In total, this first tranche consists of 28 projects. Not all projects fell in the scope of our research. Some projects were not yet completely finished. In other cases the project leader was unavailable. Another reason for disqualification was that in some projects only two partners were involved. In such a case there is no network, only a dyadic relation. With respect to the structure, coordination and communication flows, it makes a fundamental difference if you look at a dyadic level or a team/network level. Therefore, in this study only teams of three organisations or more were of interest. Finally, a number of cases was left out because the project terminated early in the process. Ultimately, 15 cases were selected and analysed (see Appendix A1 for a brief description of the cases).

\subsection{Data collection}

A mixed-method approach was used to collect data. For all fifteen projects, we conducted semi-structured interviews with the project leaders and substantiated the interview data with document analysis. The aim of the interviews was to gain insight into the different concepts of the theoretical framework, as well as into the mechanisms behind the relations between the concepts. The interviews contained open and closed questions. Closed questions invited project leaders to score project effectiveness and satisfaction on predefined scales. These questions have the advantage that they can be processed quickly and easily, and that they allow for comparison. The open questions were used on the one hand to explore the explanations behind the answers to the closed questions on effectiveness and satisfaction, and on the other hand to explore the variables of the theoretical framework. In addition, an important part of the interview was dedicated to drawing networks of interactions (relations and intensity) between project partners. The interviews lasted around an hour on average. The interviews were recorded and transcribed with help of the software programme Dragon Dictation 11.

The aim of the document analysis was to obtain information about the content as well as of the context of the project. This information was collected from project documentation (e.g. final reports, project plans) that was obtained from the project website. We replenished this with documents provided by the Knowledge for Climate programme bureau and the interview respondents.

Two of the fifteen projects were investigated more in-depth in order to present them as illustrative cases. Besides the project leaders other participants were interviewed. A 
selection of project members was made, ensuring a representation of the diverse range of organisations involved. Moreover, we attempted to include a proper balance of senior and junior participants, and academic and non-academic researchers (see Appendix A1 for a characterisation of the sample, showing that we obtained a near-complete coverage of organisations involved in two projects). The interviews had an average length of 75 minutes. The interview protocol consisted of open questions and covered the same questions as those posed to the project leaders and additional questions to 1) triangulate the degree of interactions, commitments and substantive contributions of themselves and the other project members; and 2) obtain enriched information on the history of the project.

\subsection{Data analysis}

The first step of the analysis consisted of coding of the documents and interviews through a coding scheme (see Appendix A2), which we developed based on the theoretical conceptualisation introduced in section 2. The documents and interview transcripts were read and content and context information were highlighted using the Atlas.ti software programme. Coding was done by two independent researchers. In order to establish intercoder reliability, several interviews were coded by both researchers after which the codings were compared and discussed. This resulted in a mutual understanding and refinement of the coding scheme.

The second step of the analysis was clustering all relevant data, in the form of quotes from both the interviews and documents in a large data matrix (Miles and Huberman, 1994). This clustering was structured by subcode for each project.

To be able to gain insight into the relations between the concepts as discussed in the theoretical framework we needed to combine the data of the relevant subcodes. This was done in the third step. Below we describe how we derived the aggregated measurement of concepts. For the measurement of effectiveness respondents were asked to rate the joint goal attainment, the knowledge that the project adds to the hotspot, the end report, and the extent to which expectations are achieved on a seven-point Likert scale. Based on these indicators, an overall effectiveness measure was obtained. Furthermore, the interviews were used to get a further understanding of the extent to which the objectives were realised. All parts of the interview that were related to obtaining objectives were coded as such. Based on the combination of the seven-point scale and the quotes a score was determined, ranging from low to high effectiveness.

For the measurement of satisfaction respondents were asked to rate the following dimensions of perceived project satisfaction on a seven-point Likert scale: perceived 
satisfaction about the collaboration; project partners; project structure; strength of the ties; interaction patterns; and satisfaction about goal consensus. In addition, again in-depth information from the interviews was used to determine the satisfaction within each project, ranging from low to high satisfaction.

To determine the alignment of incentives we compared for each project the incentive structure of home organisations with the incentive structure of the project team. To do so, we focused on the evaluation criteria that are being used in the project and in the home organisations. Varying scores on differences between the incentive structures were associated with low to high levels of alignment.

With respect to partner diversity we looked at several aspects including differences in disciplinary backgrounds, organisational types and normative perspectives (goals and views) of project members, as well as the level of cognitive distance between them. Moreover, we looked at the extent to which different partners had unique contributions to the project or not and if partners collaborated before. Based on these aspects, we distinguished projects with a high level of partner diversity when it appeared that partners had different disciplines and background and each partners also had a unique contribution in the project. The level of commitment of partners was based on the extent to which the partners were willing to put additional effort into the project and the extent to which partners were open to each other with respect to values, norms and/or goals. All references of the respondents to these aspects were coded. Based on these interviews quotes the coders attributed a weight to the commitment codes, signalling a level ranging from low to high. Project size is determined by the number of different organisations that are a member in the project.

With respect to project structure we made a distinction between a centralised and decentralised structure. To determine this, we asked the respondents to draw the project network and rank the frequency of interactions between the project partners. The resulting network picture revealed the extent to which a network was (de)centralised. For instance, we speak of a centralised network if one partner has relations to all project partners, but these other partners do not have relations among each other. If, however, project partners entertain mutual relations and no clear central actor can be discerned, then we label this as a decentralised network structure. To determine project management we took the following aspects into account: 1) the active management of the relations during the project; 2) the active design of meetings; 3) the active drafting of rules; the nature of the formal meeting (informing vs. discussing). The aggregated level of active project management was based on the presence of these topics. 
This scoring was done by two researchers. In most instances it was clear what score a case should be assigned. In the rare instances in which it was not obvious, the researchers discussed the scoring intensively. This resulted in a table with an overview of the scores for each variable per project (Appendix A3). This table facilitates comparison of the cases and was used to identify patterns. The analysis of this table and the associated quotations that support this analysis is presented in the following section.

\section{Results}

The analysis reveals scores for the concepts under study (see Appendix A3). The text box below provides insight into the balancing act in the two illustrative cases. These examples show the difficulties such projects have to deal with.

\section{Box: in-depth illustrations of two knowledge co-production projects}

The first project that is investigated concerns a definition study about urban heat island, i.e. the phenomenon that city areas are on average warmer than surrounding areas, and the possible repercussions for health and well-being, the so-called heat stress. A wide variety of disciplinary and organisational backgrounds was involved including meteorologists, healthcare professionals, and construction and water experts coming from seven organisations. This variety was amplified by the fact that most members met each other for the first time and even the organisations were not well-linked. This divergence made it harder to collaborate. Also, the incentives of the project partners were not so much aligned with the ones articulated in their 'home organisations'; the project focus on making urban heat research relevant to policy did not sit well with partners who used the project to create a 'showcase' for future acquisition. These divergence forces were not too much balanced by converging factors. First, the project structure was decentralised and compartimentalised, with hardly any interaction between and within the meteorology- and health-related subgroups. Second, interactions within the project were hampered by sidelined project management and individual members pursuing - and not sharing - their 'hobby horses', i.e. especially their own research methods and data. This led to anxieties in terms of interactions and mutual perceptions, and in the end to low satisfaction with project functioning. The 
diverging forces also impacted project effectiveness: the project resulted into individual showcases for the researchers, but the reception of the results ranged from ambiguous to even hostile.

The second project studied flood risks in unembanked areas. Little had been known about climate-induced rising sea levels and changes in river discharge causing higher the risks of flooding in unembanked areas. The six partners emphasised substantive creativity and playfulness as important aspects of their work. This heterogeneous set of stimuli sat awkwardly with organisation criteria like time and money budgets, leading to low alignment of incentives. This divergence was levelled out by the fact that the organisations did not vary widely in terms of disciplinary backgrounds, i.e. all focusing on water-related research. Only the project partner from the municipality was new to the field and the network but since this was the only one, he soon caught up. The group of five partners had worked with each other before and regarded this project as a stage in their continuous collaboration and collective learning. Satisfaction with past collaborations led to high partner commitment. This low level of divergence was amplified by predefined decentralised interactions and active project management along established practices. The inherent convergence led to high satisfaction with team functioning. At the same time, high in-team functioning appeared to be at the expense of relating to the context of the larger research programme deliverables, leading to moderate project effectiveness.

While exploring project performance, the analysis shows that the two dimensions under study, i.e. satisfaction and effectiveness, measure different aspects. For instance, projects with a high satisfaction do not necessarily score high on effectiveness. We observed four projects with a low level of satisfaction, four with a moderate level and seven with a high level of satisfaction. In terms of effectiveness, three projects had low performance, five had a moderate level of effectiveness, and seven a high level. In the next sections the influence of diverging and converging factors on project performance is explored.

\subsection{Embedding of the project team: alignment of incentives differences}

For all projects the evaluations of project partners' functioning inside projects were compared with the regular evaluations they experience in their 'home organisations'. Evaluation criteria that are used inside project teams include budgetary control, time management, customer satisfaction, network building, communication of results, and quality of end product. Some of these criteria were shared by participating organisations. For example, a wide range of actors 
regarded participation in the project as an opportunity to create a distinct profile for the organisation and enter new knowledge markets; they saw the project as a showcase. But different (types of) organizations also experienced some specific evaluation criteria of the 'home organisations'. For example, universities emphasised scientific publication output, whereas consultancy firms valued budgetary control, and governmental agencies focused on the relevance to their public goals, such as climate adaptation.

In about half of the projects (8) the incentives to which participants were subjected to inside the project were similar to those in their 'home organisations. As Table A.3 shows, this alignment facilitated the project in realising the objectives (effectiveness). Also in terms of satisfaction it appears to be important for projects to have alignment. In several projects, however, the incentives to which participants were subjected inside the project were different from those in their 'home organisations' (3 projects with moderate differences and 4 projects with high differences). The interviews with project leaders suggest that they rate effectiveness and satisfaction lower as differences in incentives become larger.

Interview results reveal that the two performance dimensions are not necessarily influenced in the same way. Especially project F shows a sharp difference in satisfaction and effectiveness scores, which to a certain extent can be explained by looking deeper into the alignment of incentives. It appears that the project leader conceived the process as a struggle because for one participant the incentives from the home organisation and the project were significantly different: "they were there as if they attended an engineering problem with $\mathrm{X}$ Euro and X amount of hours to spend [...] whereas the project asked for innovative and flexible contributions, and in which it is appreciated that people do more than expected.” This difference resulted in a low contribution that negatively affected the project leader's satisfaction but because this participant's contribution could be compartmentalised, it did not influence the project's effectiveness. Overall, our results indicate that small differences between incentive systems are beneficial in terms of effectiveness and satisfaction.

\subsection{Input in the project}

\subsubsection{Partner Diversity}

The transdisciplinary teams that were formed in the context of the large-scale research programme by design consisted of actors representing a wide range of organisations and disciplines. Results show that projects with the highest partner diversity scores are characterised by a large array of disciplines and organisations, which had not been combined 
before. Project M, for example, linked technical, legal and financial knowledge about multifunctional land use for water storage in the greenhouse sector. High partner diversity in project $G$ was expressed in the wide array of included knowledge users (Amsterdam Airport Schiphol and air traffic control Schiphol) and knowledge producers (two universities and the meteorology institute), and in the varying disciplinary backgrounds of the scientists (meteorology, climate predictions on larger and micro-scale).

In total 6 projects exhibited large partner diversity. We also observed 6 projects with a low diversity. The remaining 3 projects showed moderate partner diversity. Participants in projects with low diversity have matching disciplinary backgrounds. Members of project $\mathrm{N}$ “were from the same small world of water safety research (Project N)". Although they originated from distinct types of organisations, they were on the same wavelength due to a high degree of previous collaborations. Project $\mathrm{O}$ also consisted of scientific partners who knew each other from previous projects and in some cases had even been former colleagues.

Project participants emphasised the importance of diversity for these kinds of projects. The obvious reason is that diversity produces novel and creative combinations. "In order to have good results, there should at a certain moment also be some conflict or contradiction” (project E) and “in that way, we all contributed part of the answer” (project J). Another reason for partner diversity was to make sure that participants had their own and unique contribution in order to avoid conflicts: "overlapping expertise or skills results in an overlap in interests and conflicts [...] for every project member it should be clear what everybody's specific expertise is [...] that is an important prerequisite for a successful project” (project A). In other projects this reasoning can also be found: "the pie was somewhat thinly sliced [...] which in practice led to 'border clashes"” (project F) and "it was clear who had which expertise, there was no competition on expertise and skills [...] they were just complementary so they did not have to compete vehemently” (project I).

The above seems to suggest that an increase in partner diversity is beneficial to project satisfaction and effectiveness. However, when analysing Table A.3 there is also support for the alternative premise, i.e. that too much diversity can be problematic. The analysis shows that in general projects with a high diversity perform less in terms of satisfaction as well as effectiveness compared to projects with a low diversity. Interview respondents provide two reasons. First, diversity can lead to ineffectiveness because the content of the results does not match and cannot be sufficiently combined or integrated. For example, "there was no substantive basis for closer collaboration” (project M). Second, participants can differ in the answers they expect from the project, e.g. in terms of the level of uncertainty surrounding the 
results. A member of project L said: "so you go your own way and try to involve the others [...] you try them to say something but they actually do not know what to ask [...]. Actually, in climate and meteorology there are a lot of uncertainties. You cannot predict whether the wind will blow $10 \%$ harder next year [...] they were not accustomed to that way of thinking”.

At first sight, one might argue that the results are ambiguous. It is, however, important to keep in mind that these transdisciplinary teams start out with a certain level of partner diversity (i.e. 'absolute low' partner diversity is not possible). It can be argued that this is the diversity that is indicated as being beneficial by the respondents. But when the diversity increases even further, the negative consequences as described above, become relevant.

\subsubsection{Partner Commitment}

Partner commitment is revealed through the willingness to make an additional effort and expectations about efforts of other members. Such additional effort takes the form of willingness to "provide better quality” (project A) and time invested, e.g. in participating in the meetings (project $\mathrm{D}$; project $\mathrm{N}$ ). The programme philosophy dictated that participants needed to cover part of the project costs, which was for many an incentive to make extra commitments and "work faster and more effective” (project D). Furthermore, the perception of other participants’ perspectives was important. For example, "researchers hardly have a business agenda [...] they just want to do interesting work" (project A) and they were "fairly pragmatic, ambitious and have their heart in the matter" (project $\mathrm{N}$ ). They were also proactive in taking up issues and had a clear perception of roles and responsibilities (project I). This translates into the attitude participants have vis-à-vis each other: "they were open to each other and there was no competitive feeling [...]” (project D).

For most projects we observed a moderate level of commitment (9 projects). We only observed two projects with a low level and four with a high level of commitment. This low partner commitment was expressed in low meeting attendance and lacking articulation of demands and interests, which is emblematic of a reactive attitude towards the project, and the perception of the project as a secondary activity. This resulted into lower project performance (satisfaction and effectiveness). As was assumed in section 2, analysing Table A.3 reveals that high levels of partner commitment are related to higher satisfaction. We do not find the similar pattern for the association between partner commitment and effectiveness, though. Goal attainment (effectiveness) does not ask for commitment alone, but also emphasises the significance of substantive contribution. 


\subsubsection{Project size}

The projects varied from 3 to 8 participating organisations. In most cases the choice for including partners was a content-based decision, e.g. because certain disciplines or perspectives were regarded as essential to the project. Partner inclusion was a "conscious choice” (project G) and often partners "had already been working on similar topics” (project $\mathrm{D}$; project A). The knowledge users in the project had an imminent need for research on a certain topic and were therefore included; for example, "influence of weather and climate is of direct influence on our operational management” (project L). In only a few cases, project partners forced themselves into the project by introducing additional financing and/or new topics (e.g. project J).

The interview data and analysis of Table A.3 show that project size, in terms of the number of project partners, has a negative influence on the perceived satisfaction. Being part of a large project team makes it difficult to be fully aware of the progress of others and might induce opportunistic behaviour, which might result in lower satisfaction. On the other hand, project size seems to be beneficial for the effectiveness of the projects. The conscious choice of attracting additional partners, as described above, seems to pay in terms of realising objectives.

\subsection{Project governance}

The next step of our analysis was to look into the project governance. We analysed the project structure and project management. About half of the projects (8) was governed by a centralised structure, whereas the others had a decentralised structure. With respect to active project management we observed that only four projects did not display active project management. All others projects (11) were actively managed by the project leader.

We analysed if projects with a decentralised structure and/or active management were able to counteract/balance negative effects we observed above that are the result of partner diversity and project size. Our analysis does not suggest that a decentralised project structure can overcome the difficulties of a diverse and large partner set. We do observe that projects with low partner diversity are often structured in a decentralised way, whereas projects with high partner diversity have a centralised project structure. This observation suggests that project structure has a direct effect on project performance, since with exception of a few projects a decentralised structure is linked with high performance and a centralised structure with low performance. Apparently, in our empirical context, in which it is expected that knowledge is 
developed as a co-production process of universities, non-academic research institutes and societal partners, a decentralised project structure is favoured over a centralised project structure. This decentralisation might enable the necessary integration of knowledge.

With respect to project management the analysis indicates that project management might overcome some of the difficulties of a diverse partner set. However, this is not observed in all projects, e.g. not in projects with a large number of partners.

\section{Discussion and concluding remarks}

Transdisciplinary research poses an organisational challenge because this approach requires careful management of diversity and alignment. On the one hand, knowledge co-production inherently calls for divergence of disciplines, perspectives and participants, which determines the distinctive value of the approach. On the other hand, transdisciplinary research projects like any project - need to produce results that to some extent demand convergence on univocal statements. Studying these issues is important in the context of environmental sciences and policy. Dealing with environmental issues, such as local and regional climate adaptation, increasingly calls for knowledge co-production in teams involving a wide range of actors and disciplines.

This article proposes several project and contextual aspects that influence team performance, taking the interplay of divergence and convergence into account. First, team members are subject to two incentive systems: one dictated by the project principals and one by the prevailing norms in their 'home organisations'. Our findings, claiming that aligned incentive systems are beneficial for project performance, are in line with previous research. This research mostly focused on knowledge production in inter-university (Cummings and Kiesler, 2007) and university-industry collaborations (Bercovitz and Feldman, 2008), whereas our study extends the findings to transdisciplinary projects. At the same time, the dichotomy between project and 'home organisation' is relatively simplistic since there might be other actors, such as the programme management or external parties, imposing their own requests. Future research might focus on the alignment of the project with the request of those stakeholders to explore the effect of such forces. 
Second, partner diversity, partner commitment and project size form the input in a transdisciplinary process, introducing different perspectives, disciplines, etc. to the project. Our study reveals some interesting findings. For satisfaction we found that high partner commitment is important, but that larger team size has a negative effect. For effectiveness the story is different; a wider-ranging knowledge pool and more resources seem to be more important than the challenge of coping with opportunistic behaviour in large project teams. Moreover, partner commitment does not seem to impact effectiveness, indicating that substantive contribution is also valuable besides participation and effort. The association between partner diversity and project performance is more complicated; the analysis shows negative effects of high partner diversity, whereas the respondents highlighted the diversity having positive effects on creativity and avoiding conflicts.

These findings indicate that divergence only partly leads to higher project performance. One explanation for this fragmented answer lies in the selection of projects. The selected cases by definition include a wide range of organisations and disciplines, indicating that in this set of projects low partner diversity in fact still represents moderately high partner diversity. The interviews revealed that a certain diversity of project partners was required and obtained. It could well be that we only observe the right-hand side of the oftenhypothesised inverted U-shaped relation.

Project governance is expected to mitigate the diversity inherent to transdisciplinary projects in order to produce concrete end results. We used a wide range of indicators to get a deeper understanding of project governance. Based on this, we classified each project. The binary classification enabled us to compare the projects systematically. Although binary coding leads to less data richness, we used the underlying material to support our analysis of project governance.

The findings do not provide clear patterns that show project structure and project management (network-building, designing meetings, proactive drafting of rules) as having such a mitigating effect. However, there appears to be a direct effect of project structure on performance. In line with literature on teams of individuals (cf. Sparrowe et al., 2001 and Molm, 1994) we find that a decentralised project structure is favoured over a centralised project structure. Our analysis extends this association to knowledge co-production projects that can be seen as complex tasks in which the different partners need to share their knowledge. Decentralised structures facilitate this.

Several limitations of our analysis should be mentioned. First, based on the literature we selected two important dimensions of project performance: satisfaction and effectiveness. 
The results show that it was important to make a distinction, since they measure two different aspects. In future research, this operationalisation of project performance can be complemented with other conceptually distinct dimensions. An example of such dimension can be learning, which reflects a focus on changes in performance during project functioning.

Second, since the project leaders have most knowledge about the project in general, they were the most important source in our data collection with respect to the functioning of the projects. We are aware that this might result in a biased picture of the projects. We do think, however, that such bias may be limited. First, the project leaders were asked to elaborate on the performance scores. Second, the two cases that were studied more in-depth did not reveal real differences between the types of respondents on how they perceived project performance.

Third, we focused on one specific climate change programme and in order to be able to determine project performance we needed projects that were finished. This enabled us to gain insights into the effect of several project and contextual aspects on project performance. Also, the projects were characterised as more practice-driven. Future research could focus on a broader set of projects to determine to what extent the findings are context-specific.

All in all, knowledge co-production projects aim at dealing with complex societal challenges. It is important to mention that measuring collaboration and knowledge coproduction dynamics is difficult and is still in its infancy. This article contributes to understanding these dynamics and we think that our findings are relevant for projects in the environmental field with similar complex challenges because they might need to govern similar diverging and converging forces. This article focused on climate adaptation projects that inherently call for taking into account different perspectives and disciplines. Careful balancing of divergence and convergence is crucial. Our results indicate that this can best be done in the designing stage of these projects. In the context of knowledge co-production for environmental challenges, project management should consider upfront project structure, required level of partner diversity and project size. 


\section{References}

Anderson, N., De Dreu, C.K.W., Nijstad, B.A., 2004. The routinization of innovation research: a constructively critical review of the state-of-the-science. Journal of Organizational Behavior 25, 147-173.

Bakker, R.M., 2010. Taking stock of temporary organizational forms: a systematic review and research agenda. International Journal of Management Reviews 12(4), 466-486.

Baum, J.A.C., Calabrese, T., Silverman, B.S., 2000. Don’t go it alone: alliance network composition and startups’ performance in Canadian biotechnology. Strategic Management Journal 21, 267-294.

Bercovitz, J., Feldman, M., 2011. The mechanisms of collaboration in inventive teams: composition, social networks, and geography. Research Policy 40(1), 81-93.

Biesbroek, G.R., Swart, R.J., et al., 2010. Europe adapts to climate change: comparing national adaptation strategies. Global Environmental Change 20(3), 440-450.

Boon, W.P.C., Moors, E.H.M., Kuhlmann, S., \& Smits, R.E.H.M., 2011. Demand articulation in emerging technologies: Intermediary user organisations as co-producers? Research Policy 40(2), 242-252.

Brown, S.L., Eisenhardt, K.M., 1995. Product development: past research, present findings, and future directions. Academy of Management Review 20, 343-378.

Chompalov, I., Genuth, J., Shrum, W., 2002. The organization of scientific collaborations. Research Policy 31(5), 749-767.

Cohen, S.G., Bailey,D.E., 1997. What makes teams work: Group effectiveness research from the shop floor to the executive suite. Journal of Management 23, 239-290. 
Cohen, W.M., Levinthal, D.A., 1990. Absorptive capacity: a new perspective on learning and innovation. Administrative science quarterly 35, 128-152.

Cooke-Davies, T., 2002. The “real” success factors on projects. International journal of project management 20, 185-190.

Cummings, J.N., Kiesler, S., 2007. Coordination costs and project outcomes in multiuniversity collaborations. Research Policy 36(10), 1620-1634.

Curseu, P.L., Jansen, R.J.G., Chappin, M.M.H., 2013. Decision rules and group rationality: cognitive gain or standstill? PLoS ONE 8(2), 1-7.

Dahlin K.B., Weingart, L.R., Hinds, P.J., 2005. Team diversity and information use. Acad. Manage. J. 48, 1107-1123.

De Wit, A., 1988. Measurement of project success. Project Management 6(3), 164-170.

Edelenbos, J., Van Buuren, A., Van Schie, N., 2011. Co-producing knowledge: joint knowledge production between experts, bureaucrats and stakeholders in Dutch water management projects. Environmental Science and Policy 14, 675-684.

Ericksen, J., Dyer, L., 2004. Right from the start: exploring the effects of early team events on subsequent project team development and performance. Adm Sci Q 49, 438-471.

Ford, J.D., Berrang-Ford, L., Paterson, J., 2011. A systematic review of observed climate change adaptation in developed nations. Climate Change, 1-10.

Gilsing, V., Nooteboom, B., Haverbeke, W., Duysters, G., Van den Oord, A., 2008. Network embeddedness and the exploration of novel technologies: technological distance, betweenness centrality and density. Research Policy 37, 1717-1731.

Hackman, J.R., 1987. The design of work teams, in: Lorsch, J.W. (Ed.), Handbook of organizational behavior. Prentice-Hall, Englewood Cliffs, pp. 67-102.

Hara, N., Solomon, P., 2003. An emerging view of scientific collaboration: scientists’ perspectives on collaboration and factors that impact collaboration. Journal of the American society for information science and technology 54, 952-965. 
Hegger, D., Lamers, M., Van Zeijl-Rozema, A., Dieperink, C., 2012a. Conceptualising joint knowledge production in regional climate change adaptation projects: success conditions and levers for action. Environmental science \& policy 15(1), 52-65.

Hegger, D., Van Zeijl-Rozema, A., Dieperink, C., 2012b. Toward design principles for joint knowledge production projects: lessons from the deepest polder of The Netherlands. Regional Environmental Change, 1-14.

Hobday, M., 2000. The project-based organization: an ideal form for managing complex products and systems? Research Policy 29, 871-893.

Hoegl, M., Germeunden, H.G., 2001. Teamwork Quality and the Success of Innovative Project: A Theoretical Concept and Empirical Evidence. Organization Science 12(4), 435499.

Ibert, O., 2004. Projects and firms as discordant complements: organisational learning in the Munich software ecology. Research Policy 33, 1529-1546.

Jones, C., Lichtenstein, B.B., 2008. Temporary interorganizational projects: how temporal and social embeddedness enhance coordination and manage uncertainty. Oxford University Press, Oxford.

Kabat, P., Van Vierssen, W., Veraart, J., Vellinga, P., Aerts, J., 2005. Climate proofing the Netherlands. Nature, 438(7066), 283.

Kenis, P., Provan, K.G., 2009. Towards an exogenous theory of public network performance. Public Administration 87(3), 440-456.

Levering, R.C., Ligthart, R., Noorderhaven, N.G., Oerlemans, L.A.G., 2013. Continuity and change in interorganizational project practices: the Dutch shipbuilding industry, 1950-2010. International Journal of Project Management 31(5), 735-747.

Levine, J.M., Moreland, R.L., 1990. Progress in small group research. Annual Review of Psychology 41, 585-634.

March, J.G., 1991. Exploration and exploitation in organizational learning. Organization Science 2(1), 71-87. 
McNie, E.C., 2007. Reconciling the supply of scientific information with user demands: an analysis of the problem and review of the literature. Environmental Science \& Policy, 10(1), 17-38.

Miles, M.B., Huberman, A.M. 1994. Qualitative data analysis: an expanded sourcebook. Sage, Thousand Oaks, CA.

Molm, L.D., 1994. Dependence and risk: Transforming and structure of social exchange. Social Psychology Quarterly 57, 163-176.

Nooteboom, B., 1999. Inter-firm alliances: analysis and design. Routledge, London.

Nowotny, H., Scott, P., 2001. Re-thinking science: knowledge and the public in an age of uncertainty. Polity Press, Cambridge.

Parker, J.N., Vermeulen, N., Penders, B., 2010. Collaboration in the new life sciences. Ashgate, Aldershot.

Pohl, C., 2008. From science to policy through transdisciplinary research. Environmental Science and Policy 11(1), 46-53.

Pohl, C., Rist, S., et al, 2010. Researchers' roles in knowledge co-production: experience from sustainability research in Kenya, Switzerland, Bolivia and Nepal. Science and Public Policy, 37(4), 267-281.

Provan, K.G., Fish, A., 2007. Interorganizational networks at the network level: A review of the empirical literature on whole networks. Journal of Management 33(3): 479-516.

Provan, K.G., Milward, H.B., 2001. Do networks really work? A framework for evaluating public-sector organizational networks. Public Administration Review 61, 414-423.

Roelofsen, A., Boon, W.P.C., Broerse, J., Kloet, R., 2011. Stakeholder interaction within research consortia on emerging technologies: learning how and what? Research Policy 40(3), 341-354.

Sarewitz, D., 2004. How science makes environmental controversies worse. Environmental Science and Policy 7, 385-403. 
Sarewitz, D., Pielke, R.A., 2007. The neglected heart of science policy: reconciling supply and demand for science. Environmental Science and Policy 10, 5-16.

Sparrowe, R.T., Liden, R.C., Wayne, S.J., Kraimer, M.L., 2001. Social networks and the performance of individuals and groups. Academy of Management Journal 44, 316-325.

Stokols, D., Misra, S. et al., 2008. The ecology of team science - Understanding contextual influences on transdisciplinary collaboration. American Journal of Preventive Medicine 35(2), S96-S115.

Uzzi, B., 1997. Social structure and competition in interfirm networks: the paradox of embeddedness. Administrative Science Quarterly 42(1), 35-67

Verbree, M., 2011. Dynamics of academic leadership in research groups. Rathenau Instituut, Den Haag.

Wuyts, S., Colombo, M.G., Dutta, S., Nooteboom, B., 2005. Empirical test of optimal cognitive distance. Journal of Economic Behavior and Organization 28, 277-302.

Zaheer, A., McEvilly, B., Perrone, V., 1998. Does trust matter? Exploring the effects of interorganizational and interpersonal trust on performance. Organizational Science 9(2), 141159. 
Appendix A1: overview of project topics

Table A.1: overview project topics.

\begin{tabular}{|c|c|c|}
\hline $\begin{array}{l}\text { Project } \\
\text { no. }{ }^{\text {a) }}\end{array}$ & \multicolumn{2}{|l|}{ Project description } \\
\hline \multirow[t]{6}{*}{1} & \multicolumn{2}{|c|}{$\begin{array}{l}\text { Definition study Water safety unembanked areas } \\
\text { This project was investigated in depth. Overview of number of actors } \\
\text { interviewed (/number of organisations involved in the project) per organisation } \\
\text { type: }\end{array}$} \\
\hline & Public agencies & \begin{tabular}{|l|l}
$1 / 1$ \\
\end{tabular} \\
\hline & University & $3 / 2$ \\
\hline & Research institute (non-profit) & $2 / 2$ \\
\hline & Consultancy firm or engineering agency & $0 / 1$ \\
\hline & Company & $0 / 0$ \\
\hline 2 & \multicolumn{2}{|c|}{$\begin{array}{l}\text { Relationship between perceived flood risks, problem ownership and household } \\
\text { and business adaptation choices }\end{array}$} \\
\hline 3 & \multicolumn{2}{|c|}{ Safe levee systems } \\
\hline 4 & \multicolumn{2}{|l|}{ Urban development - Urban water systems } \\
\hline 5 & \multicolumn{2}{|c|}{ Future of the fen meadow area } \\
\hline 6 & \multicolumn{2}{|c|}{ Region specific climate information for Haaglanden and Rotterdam } \\
\hline 7 & \multicolumn{2}{|c|}{ Climate in spatial decision making } \\
\hline 8 & \multicolumn{2}{|c|}{ Adaptation to Meuse flood risk } \\
\hline \multirow[t]{6}{*}{9} & \multicolumn{2}{|c|}{$\begin{array}{l}\text { Heat stress in the city of Rotterdam } \\
\text { This project was investigated in depth. Overview of respondents: }\end{array}$} \\
\hline & Public agencies & $1 / 2$ \\
\hline & University & $1 / 1$ \\
\hline & Research institute (non-profit) & $1 / 1$ \\
\hline & Consultancy firm or engineering agency & $2 / 2$ \\
\hline & Company & $1 / 1$ \\
\hline 10 & \multicolumn{2}{|c|}{ Climatology and climate scenarios Mainport Schiphol } \\
\hline 11 & \multicolumn{2}{|c|}{$\begin{array}{l}\text { Broad, region specific reconnaissance of effects of climate change in relation to } \\
\text { future scenarios and trends }\end{array}$} \\
\hline 12 & \multicolumn{2}{|c|}{$\begin{array}{l}\text { Combining spatial claims of land use functions and adaptive strategies to climate } \\
\text { change in densely populated rural areas }\end{array}$} \\
\hline 13 & \multicolumn{2}{|c|}{ Consequences of climate change for inland shipping } \\
\hline 14 & \multicolumn{2}{|c|}{$\begin{array}{l}\text { Demonstration project multifunctional land use for water storage in the } \\
\text { greenhouse sector }\end{array}$} \\
\hline 15 & \multicolumn{2}{|c|}{$\begin{array}{l}\text { The impact of climate change on the critical weather conditions at Schiphol } \\
\text { airport }\end{array}$} \\
\hline
\end{tabular}


Appendix A2: Coding scheme

Table A.2: Coding scheme.

\begin{tabular}{|c|c|}
\hline Main code & Subcode \\
\hline \multirow[t]{4}{*}{ General information project } & Number of project partners \\
\hline & Available financial resources \\
\hline & Duration of project \\
\hline & Leverage of team members inside home organisation \\
\hline \multirow[t]{2}{*}{ Cognitive leadership of Project leader } & Visioning (active steering by project leader) \\
\hline & Scope (delineation of goal and research question by project leader) \\
\hline \multirow[t]{5}{*}{ Project management } & Locus of start of initiative \\
\hline & Management of relations \\
\hline & Design meetings \\
\hline & Drafting of rules \\
\hline & Nature of interaction in meetings \\
\hline \multirow[t]{3}{*}{ Communication in general } & Length formal meetings \\
\hline & Frequency formal meetings \\
\hline & Frequency bilateral meetings \\
\hline \multirow[t]{3}{*}{ Structural characteristics } & Centralised structure \\
\hline & Collaborative structure \\
\hline & Task division (complementary vs. integrative) \\
\hline \multirow[t]{7}{*}{ Team diversity } & Disciplinary background of partners \\
\hline & Cognitive distances between partners \\
\hline & Corresponding values, norms and/or goals of partners \\
\hline & Corresponding view on science-society nexus \\
\hline & Different types of organisations \\
\hline & Unique contributions of partners in project \\
\hline & Previous acquaintance of partners \\
\hline \multirow[t]{3}{*}{ Partner commitment } & Investment of effort of partners \\
\hline & Openness to other actors' values, norms and/or goals \\
\hline & Expectations about others \\
\hline \multirow[t]{4}{*}{ Alignment of incentive systems } & Differences incentives programme vs. project leader \\
\hline & Differences incentives programme vs. team \\
\hline & Differences incentives home organization vs. project leader \\
\hline & Differences incentives home organization vs. team \\
\hline \multirow[t]{4}{*}{ Effectiveness } & Joint goal attainment \\
\hline & Hotspot knowledge achievement \\
\hline & End report achievement \\
\hline & Expectation achievement \\
\hline \multirow[t]{6}{*}{ Satisfaction } & Satisfaction collaboration \\
\hline & Satisfaction of others about collaboration \\
\hline & Satisfaction structure \\
\hline & Satisfaction strength of ties \\
\hline & Satisfaction interaction \\
\hline & Satisfaction goal consensus \\
\hline Expectations & $\begin{array}{l}\begin{array}{l}\text { Expectations about usefulness of team's output for home } \\
\text { organisation }\end{array} \\
\end{array}$ \\
\hline \multirow[t]{2}{*}{ Effort to transfer results } & Effort into transfer to home organisation \\
\hline & Effort into transfer to hotspot/stakeholders/others \\
\hline
\end{tabular}




\section{Appendix A3: table with variable scores}

Table A.3: overview of the scores for each variable per project

\begin{tabular}{|c|c|c|c|c|c|c|c|c|}
\hline \multirow[t]{2}{*}{ Case } & \multirow{2}{*}{$\begin{array}{l}\text { Incenti } \\
\text { ve } \\
\text { differe } \\
\text { nces }\end{array}$} & \multicolumn{3}{|c|}{ Project input } & \multicolumn{2}{|c|}{ Project governance } & \multicolumn{2}{|c|}{ Project performance } \\
\hline & & $\begin{array}{l}\text { Partner } \\
\text { diversity }\end{array}$ & $\begin{array}{l}\text { Partner } \\
\text { commitment }\end{array}$ & $\begin{array}{l}\text { Project } \\
\text { size }\end{array}$ & Project structure & $\begin{array}{l}\text { Project } \\
\text { management }\end{array}$ & Satisfaction & $\begin{array}{l}\text { Effectiven } \\
\text { ess }\end{array}$ \\
\hline A & low & high & high & 5 & centralised & yes & moderate & low \\
\hline B & low & low & moderate & 4 & centralised & yes & high & high \\
\hline $\mathrm{C}$ & $\begin{array}{l}\text { moder } \\
\text { ate }\end{array}$ & $\begin{array}{l}\text { moderat } \\
\mathrm{e}\end{array}$ & moderate & 5 & centralised & yes & moderate & high \\
\hline $\mathrm{D}$ & low & $\begin{array}{l}\text { moderat } \\
\mathrm{e}\end{array}$ & high & 6 & decentralised & yes & high & high \\
\hline $\mathrm{E}$ & low & low & moderate & 3 & decentralised & yes & high & moderate \\
\hline $\mathrm{F}$ & high & low & moderate & 8 & centralised & no & low & high \\
\hline G & low & high & moderate & 5 & centralised & yes & moderate & high \\
\hline $\mathrm{H}$ & low & low & moderate & 6 & decentralised & no & high & high \\
\hline I & high & high & high & 5 & decentralised & yes & high & low \\
\hline $\mathrm{J}$ & $\begin{array}{l}\text { moder } \\
\text { ate }\end{array}$ & high & moderate & 7 & centralised & yes & low & moderate \\
\hline K & high & $\begin{array}{l}\text { moderat } \\
\text { e }\end{array}$ & moderate & 7 & decentralised & no & low & moderate \\
\hline $\mathrm{L}$ & $\begin{array}{l}\text { moder } \\
\text { ate }\end{array}$ & high & low & 3 & centralised & no & low & low \\
\hline M & low & high & low & 7 & centralised & yes & moderate & moderate \\
\hline $\mathrm{N}$ & high & low & high & 6 & decentralised & yes & high & moderate \\
\hline $\mathrm{O}$ & low & low & moderate & 4 & decentralised & yes & high & high \\
\hline
\end{tabular}




\section{Illustration captions}

Table A.1: overview project topics.

Table A.2: Coding scheme.

Table A.3: overview of the scores for each variable per project. 